Tema: Aciaria Oxigênio

\title{
TECNOLOGIA DE PRODUÇÃO DE AÇOS COM ULTRA BAIXOS TEORES DE HIDROGÊNIO*
}

Bruno Rodrigues Henriques ${ }^{1}$

\begin{abstract}
Resumo
Este trabalho apresenta a tecnologia de produção de aços com ultra baixos teores de hidrogênio (2 ppm máx) que foi desenvolvida na ArcelorMittal Tubarão. Esta tecnologia foi implementada em duas etapas: a primeira etapa consistiu no controle das principais fontes de incorporação de hidrogênio no aço líquido e a segunda etapa contemplou a adoção de práticas especiais de aciaria, visando-se obter o mais baixo teor de hidrogênio possível no aço líquido, no fim do tratamento no $\mathrm{RH}$. As principais fontes de incorporação de hidrogênio foram identificadas e quantificadas. Foram desenvolvidos modelos matemáticos para prever os teores de hidrogênio no início e no fim do tratamento no $\mathrm{RH}$. As práticas especiais de aciaria e o restrito controle de qualidade em cada fase do processo proporcionaram um teor médio de hidrogênio de apenas 1,09 ppm no fim do tratamento no $\mathrm{RH}$. A incorporação de hidrogênio, durante o processo de lingotamento, foi minimizada.
\end{abstract}

Palavras-chave: Hidrogênio; Pick-up de hidrogênio; Hidrogênio no aço; HIC.

\section{PRODUCTION TECHNOLOGY OF ULTRA LOW HYDROGEN STEEL GRADES}

\begin{abstract}
This paper presents the production technology of ultra-low ( $2 \mathrm{ppm}$ max) hydrogen steel grades that has been developed at ArcelorMittal Tubarão. This technology was implemented in two steps: first step has considered the control of the main hydrogen pickup sources into liquid steel and the second step was the adoption of key steelmaking practices, in order to reach the lowest possible hydrogen content in the steel, at end of RH treatment. The main hydrogen pickup sources were identified and quantified. It were developed mathematical models to predict the hydrogen contents at beginning and end of $\mathrm{RH}$ treatment. The special steelmaking practices and the stringent quality control at each stage of the process have guaranteed an average hydrogen content of only 1,09 ppm at end of $\mathrm{RH}$ treatment. The hydrogen pickup, during casting, was minimized.
\end{abstract}

Keywords: Hydrogen; Hydrogen pickup; Hydrogen in the steel, HIC.

1 Engenheiro Metalurgista, Gerência Geral de Produção de Aço, ArcelorMittal Tubarão, Serra, ES, Brasil.

* Contribuição técnica ao $45^{\circ}$ Seminário de Aciaria - Internacional, 25 a 28 de maio de 2014, 


\section{INTRODUÇÃo}

\subsection{Apresentação}

Com o aperfeiçoamento das práticas de metalurgia de panela, hoje é possível produzir aços que apresentem extrema limpidez e controle apurado do teor da maioria dos elementos químicos. Contudo, a remoção e o controle, em baixos níveis, dos gases dissolvidos no aço ainda possui um grau significativo de dificuldade. 0 controle do teor de hidrogênio, em níveis modestos, sem a etapa de desgaseificação ou então a redução do teor de hidrogênio para valores abaixo de 1,5 ppm ainda são grandes desafios para a maioria das aciarias do mundo.

Segundo Warren [1], o hidrogênio pode entrar e sair do aço sem que sua presença tenha sido notada, ou pode provocar danos severos que, dependendo das circunstâncias, podem ser descritos como: bolhas, flocos ou escamas, fragilização, fissuras, trincas internas, etc. Fuji [2], por sua vez, afirma que o hidrogênio talvez seja, dentre todos os elementos residuais na fabricação do aço, o único considerado sempre prejudicial às propriedades físicas e mecânicas do produto final.

Os efeitos deletérios do hidrogênio no aço e os mecanismos que os explicam, apesar de estudados e discutidos há décadas, ainda permanecem como temas de grande relevância, haja vista a grande quantidade de trabalhos técnicos que atualmente ainda abordam esse assunto.

Aços para "sour service", por exemplo, precisam apresentar mínimos teores de hidrogênio dissolvido, de modo que possam apresentar alta resistência ao fenômeno de trincamento induzido pelo hidrogênio. Neste contexto, com foco nos aços com ultra baixos teores de hidrogênio, torna-se imperativo o desenvolvimento de técnicas especiais de produção na aciaria, visando minimizar a incorporação de hidrogênio em cada etapa do ciclo produtivo e ao mesmo tempo maximizar o processo de remoção de hidrogênio, durante o tratamento da corrida sob vácuo.

\subsection{Objetivos}

O objetivo geral deste trabalho é o de desenvolver, na aciaria da ArcelorMittal Tubarão, uma tecnologia de produção de aços com ultra baixos teores de hidrogênio, ou seja, aços com teores máximos de 2ppm, medidos no distribuidor do lingotamento contínuo. Para tanto, tem-se os seguintes objetivos específicos:

- Identificar, quantificar e controlar as principais fontes de incorporação de hidrogênio no aço líquido, atuantes em todas as etapas do ciclo produtivo.

- Maximizar a taxa de remoção de hidrogênio, na etapa de desgaseificação sob vácuo, visando a obtenção de teores de hidrogênio abaixo de 1,2ppm.

\subsection{Revisão da Literatura}

\subsubsection{Solubilidade do hidrogênio no aço}

A solubilidade do hidrogênio em metais é uma função da forma física do metal (sólido $x$ líquido), do reticulado cristalino, do teor de elementos de liga, da temperatura e da pressão parcial de hidrogênio do meio ambiente.

\subsubsection{Influência da pressão parcial de hidrogênio}

O hidrogênio, na forma atômica, se dissolve nas ligas de ferro líquido de acordo com a Equação 1.

* Contribuição técnica ao 45 Seminário de Aciaria - Internacional, 25 a 28 de maio de 2014, 


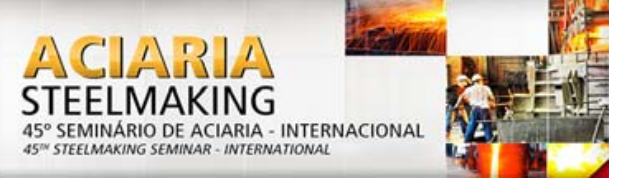

$$
\frac{1}{2} H_{2(g)} \Rightarrow \underline{H}
$$

A concentração de hidrogênio presente no banho metálico é relacionada com a pressão parcial de gás, através da seguinte relação (Equação 2):

$$
[\% \mathrm{H}]=\frac{K_{H}}{f_{H}} \sqrt{P_{H 2}}
$$

Onde:

- $[\% \mathrm{H}]$ : Concentração de hidrogênio (em \% peso);

- $K_{H}$ : Constante de equilíbrio a uma dada temperatura;

- $f_{H}$ : Coeficiente de atividade henriana do hidrogênio;

- $\quad P_{\mathrm{H}_{2}}$ : Pressão parcial de hidrogênio no aço (em atm).

Segundo Fuwa [3], que realizou uma grande compilação de dados de literatura, o valor da constante de equilíbrio $\left(\mathrm{K}_{H}\right)$ é obtido pela seguinte expressão (Equação 3):

$$
\log K_{H}=-\frac{1900}{T}-1,577
$$

Onde T é a temperatura em graus Kelvin.

O coeficiente de atividade do hidrogênio dissolvido em ligas de ferro líquido é dado pela seguinte somatória (Equação 4):

$$
\log f_{H}=\sum e_{H}^{j}[\% j]
$$

onde $e_{H}^{j}$ é o coeficiente de interação henriano de"j" sobre o elemento hidrogênio.

\subsubsection{Influência da Temperatura}

A Figura 1 mostra o efeito da temperatura sobre a solubilidade do hidrogênio no ferro, na pressão de 1 atm [4].

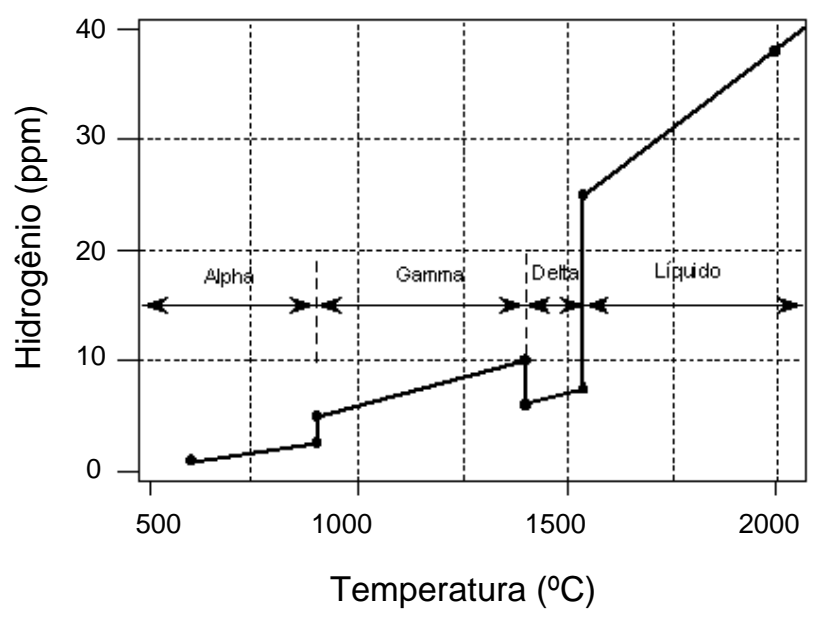

Figura 1. Solubilidade do hidrogênio no ferro, em função da temperatura, na pressão de 1atm [4].

* Contribuição técnica ao $45^{\circ}$ Seminário de Aciaria - Internacional, 25 a 28 de maio de 2014, 


\section{MATERIAIS E MÉTODOS}

O teor de hidrogênio presente no aço líquido, e medido no distribuidor do lingotamento contínuo, é decorrente da influência de duas variáveis metalúrgicas:

- Variável 1: Teor de hidrogênio obtido no fim do tratamento da corrida, na estação de desgaseificação a vácuo $(\mathrm{RH})$.

- Variável 2: Incorporação de hidrogênio no aço líquido, que ocorre entre o fim do tratamento no $\mathrm{RH}$ e o fim do lingotamento da corrida.

Ou seja, o teor de hidrogênio medido no contínuo pode ser descrito através da Equação 5.

$$
\mathrm{H} \text { (contínuo })=\text { Teor final de } \mathrm{H} \text { no RH + Incorporação de H no contínuo }
$$

Portanto, de forma geral, o desenvolvimento de uma tecnologia de produção de aços com ultra baixos teores de hidrogênio, precisa minimizar a influência das duas variáveis descritas acima.

Para minimizar a influência da variável 1, ou seja, para se obter o mais baixo teor de hidrogênio possível no fim do tratamento no RH é preciso o seguinte:

- Identificar, quantificar e controlar todas as fontes de incorporação de hidrogênio no aço líquido, que estejam atuando durante os processos de sopragem e vazamento do aço líquido no convertedor LD, assim como durante o transporte da panela de aço do convertedor até o $\mathrm{RH}$.

- Desenvolver práticas operacionais diferenciadas, específicas para as etapas de sopragem e vazamento do aço líquido, de modo que a maior parte da incorporação de hidrogênio no aço líquido ocorra antes do início de tratamento no RH.

- Otimizar o processo de remoção de hidrogênio durante o tratamento da corrida no $\mathrm{RH}$, de modo a garantir o mínimo teor possível de hidrogênio no fim do tratamento da corrida.

Por sua vez, para minimizar a influência da variável 2, ou seja, para que a incorporação de hidrogênio seja a mínima possível, é preciso identificar, quantificar e controlar todas as fontes de incorporação de hidrogênio no aço líquido, que estejam atuando durante o processo de lingotamento da corrida.

A metodologia de estudos, experimentos e testes, que será descrita a seguir, leva em consideração todos os conceitos e premissas apresentados até este momento.

\subsection{Metodologia para o Estudo da Incorporação de Hidrogênio entre o Convertedor e a Estação de Desgaseificação a Vácuo}

Para se estudar o processo de incorporação de hidrogênio que ocorre entre o fim de sopro no convertedor e o início de tratamento da panela de aço no $\mathrm{RH}$, decidiu-se pela implementação de uma série de experimentos, realizados na panela de aço de 315t, durante e após o vazamento do aço líquido proveniente do convertedor.

\subsubsection{Variáveis utilizadas nos experimentos}

As variáveis escolhidas para serem utilizadas nos experimentos apresentam, segundo dados de literatura, influência relevante na incorporação de hidrogênio no aço líquido. Além disso, todas as variáveis utilizadas são passíveis de controle, de modo que os valores das mesmas possam estar de acordo com o que estabelece cada plano de experimento. As variáveis que foram utilizadas nos experimentos são

* Contribuição técnica ao 45 Seminário de Aciaria - Internacional, 25 a 28 de maio de 2014, 


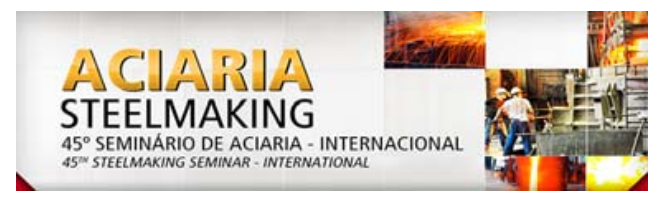

as seguintes: Peso de cal adicionado durante o vazamento do aço líquido; Peso de FeSiMn e de ligas de Fe-Mn adicionado durante o vazamento do aço; Peso de material recarburante adicionado durante o vazamento do aço e Condição de vazamento do aço líquido (acalmado ou efervescente).

\subsubsection{Plano de experimentos}

O plano de experimentos previa a realização de um total de 9 grupos de experimentos, com um número mínimo de 6 experiências conduzidas em cada grupo. Cada experiência foi executada em apenas uma corrida e cada variável utilizada foi dividida em dois níveis de valores (N1 e N2).

\subsubsection{Variável resposta dos experimentos}

A variável resposta de cada experiência foi o teor de hidrogênio presente no aço líquido. O teor de hidrogênio foi medido no $\mathrm{RH}$, antes do início do tratamento, utilizando-se o sistema Hydris de medição [5]. Os resultados obtidos foram correlacionados com as variáveis utilizadas nos experimentos.

\subsection{Metodologia para o Estudo da Incorporação de Hidrogênio entre a Estação de Desgaseificação a Vácuo e o Ling. Contínuo}

Para se quantificar a influência das principais fontes de incorporação de hidrogênio no aço líquido, que estejam atuando entre o fim do tratamento no $\mathrm{RH}$ e o fim do lingotamento da corrida, foram realizados vários experimentos, tendo-se o teor de hidrogênio medido no distribuidor (com o sistema Hydris) como variável resposta, utilizando-se principalmente as primeiras corridas dos distribuidores.

\subsection{Metodologia para Maximização da Taxa de Remoção de $\mathbf{H}_{2}$}

Através de metodologia six-sigma (Black Belt), foi conduzido um extenso trabalho técnico, com o intuito de se definir procedimentos operacionais visando a obtenção do mínimo teor de hidrogênio no aço líquido, no fim do tratamento no RH. Como ponto de partida, definiu-se que o problema a ser estudado seria a obtenção de teor de hidrogênio acima do permitido. O processo gerador do problema foi estudado em profundidade, as causas fundamentais foram identificadas e quantificadas, e as soluções prioritárias foram definidas. Em seguida, implementou-se um teste piloto, foram avaliados os efeitos correlatos, definiu-se uma solução em larga escala para o problema analisado e, finalmente, realizou-se um teste em escala industrial.

\section{RESULTADOS E DISCUSSÃO}

\subsection{Resultados dos Experimentos (Entre Convertedor e RH)}

No total, foram realizadas 69 experiências, divididas em 9 grupos de experimentos. A Tabela 1 mostra, de forma global, os resultados obtidos. Os campos tracejados indicam que aquela variável não foi utilizada no grupo de experimentos.

* Contribuição técnica ao 45 Seminário de Aciaria - Internacional, 25 a 28 de maio de 2014, 


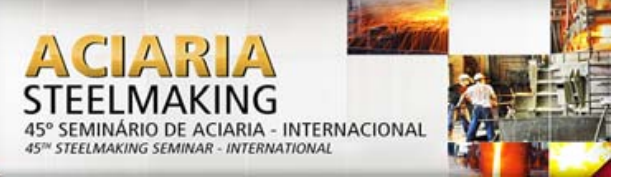

Tabela 1. Resultados gerais de todos os grupos de experimentos

\begin{tabular}{|c|c|c|c|c|c|c|c|}
\hline \multirow[t]{2}{*}{ Grupo } & \multirow[t]{2}{*}{ Vaz. } & \multirow{2}{*}{$\begin{array}{l}\text { Cal } \\
\text { (kg) }\end{array}$} & \multicolumn{2}{|c|}{ Ferro-Ligas (kg) } & \multicolumn{2}{|c|}{ Recarburantes (kg) } & \multirow{2}{*}{$\begin{array}{c}\mathrm{H} \\
(\mathrm{ppm})\end{array}$} \\
\hline & & & FeSiMn & FeMn & Coque & Grafite & \\
\hline $1^{0}$ & EF & ---- & ---- & ---- & ---- & ---- & 1,7 \\
\hline $2^{0}$ & EF & 654 & ---- & ---- & ---- & ---- & 1,9 \\
\hline $3^{\circ}$ & $A C$ & ---- & ---- & ---- & ---- & ---- & 2,0 \\
\hline $4^{\circ}$ & $A C$ & 599 & ---- & ---- & ---- & ---- & 2,2 \\
\hline $5^{\circ}$ & $A C$ & 571 & ---- & 793 & ---- & ---- & 2,9 \\
\hline $6^{\circ}$ & $A C$ & 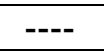 & 5727 & ---- & ---- & ---- & 4,0 \\
\hline $7^{0}$ & $A C$ & $\begin{array}{ll}--- \\
\end{array}$ & 3132 & ---- & 1521 & ---- & 5,2 \\
\hline $8^{\circ}$ & $A C$ & 2842 & 4337 & 1630 & ---- & ---- & 5,3 \\
\hline $9^{\circ}$ & $A C$ & 2014 & 2337 & ---- & ---- & 1475 & 5,4 \\
\hline
\end{tabular}

Onde:

- Vaz.: Condição de vazamento do aço líquido;

- EF: Vazamento efervescente (sem adição de alumínio);

- AC: Vazamento acalmado (com adição de alumínio);

- Ao se analisar os resultados dos experimentos, verifica-se que as variáveis mencionadas anteriormente foram capazes de elevar o teor médio de hidrogênio de 1,7 para 5,4ppm, mostrando o quão influentes são as mesmas no processo de incorporação de hidrogênio no aço líquido.

$\mathrm{Na}$ verdade, como os experimentos foram planejados com base em dados de literatura, já se esperava essa gradação de valores que foi observada. Verifica-se que os maiores valores de hidrogênio foram obtidos nos experimentos que utilizaram grandes adições de materiais, seja de cal, ferro-ligas ou materiais recarburantes.

A Figura 2 mostra uma disposição gráfica do tipo "Box-Plot", para a mediana, onde se pode avaliar a simetria e a dispersão dos resultados do teor médio de hidrogênio presente no aço líquido, para cada grupo de experimentos.

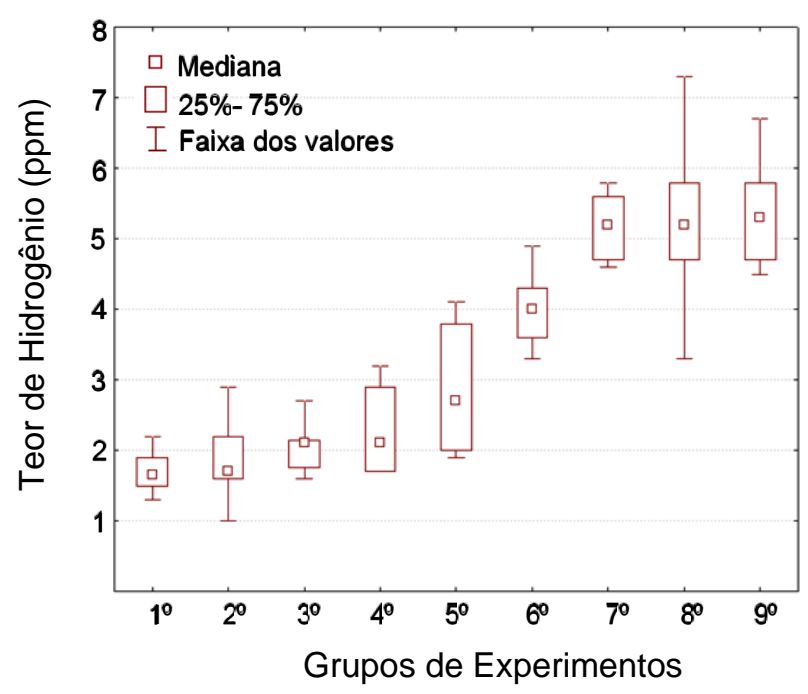

Figura 2. Box-Plot (da mediana) mostrando a distribuição dos resultados de hidrogênio.

A Figura 3, mostrada a seguir, apresenta uma disposição gráfica do tipo "Box-Plot", para a média, onde se podem fazer inferências sobre as médias de cada um dos grupos de experimentos realizados nesse estudo.

* Contribuição técnica ao $45^{\circ}$ Seminário de Aciaria - Internacional, 25 a 28 de maio de 2014, 

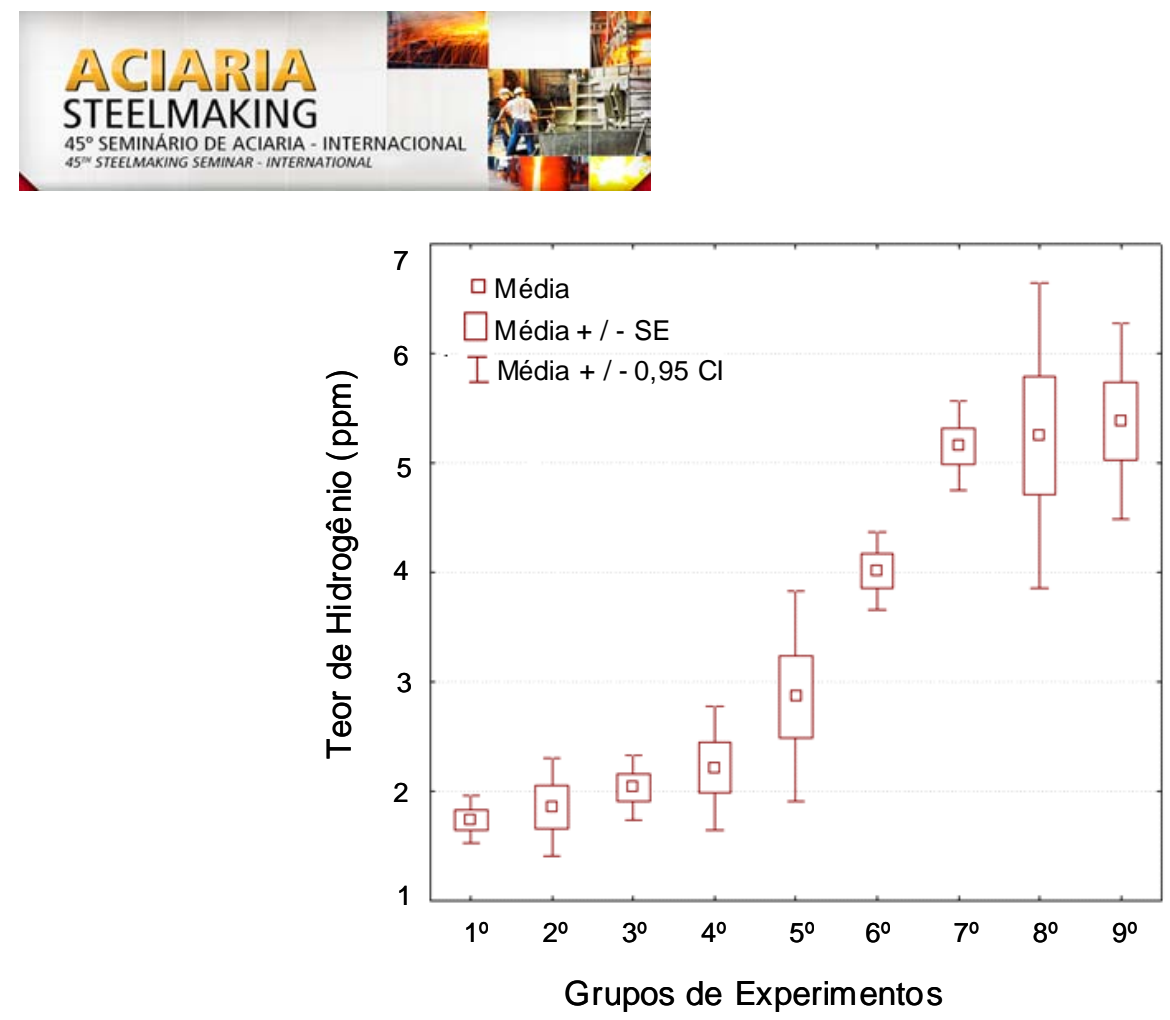

Figura 3. Box-Plot (da média) mostrando a distribuição dos resultados de hidrogênio.

Nesse momento da análise dos resultados, foi possível concluir que praticamente todas as variáveis incluídas no plano de experimentos tinham influência na incorporação de hidrogênio no aço líquido. A análise da importância relativa de cada variável em relação às demais e o efeito de cada uma delas no teor final de hidrogênio só se tornou possível através da análise de regressão linear múltipla.

\subsubsection{Modelo de previsão do teor inicial de hidrogênio no RH}

Para quantificar/ratificar a importância das variáveis já identificadas e para avaliar a influência de variáveis não incluídas nos experimentos, decidiu-se pela realização de uma análise de regressão linear múltipla. Para tanto, além das variáveis incluídas nos planos de experimentos, foram considerados também os seguintes parâmetros: índice de ressopro; adição de cal e dolomita crua no convertedor; adição de dolomita na panela; adição de FeSi na panela e teor de umidade relativa do ar. No total, para a análise de regressão linear múltipla, foram consideradas 15 variáveis preditoras.

O modelo de regressão que procura fazer a predição do teor de hidrogênio presente no aço líquido, no início do tratamento no $\mathrm{RH}$, está apresentado abaixo:

$$
\begin{aligned}
& H=1,738136+(0,0003 \times \text { SiMn })+\left(0,000631 \times \mathrm{Cal}_{\mathrm{p}}\right)+(0,001637 \times \text { Coque }) \\
& +\left(0,000576 \times \mathrm{Cal}_{\mathrm{ld}}\right)+(0,000905 \times \text { Grafite })+\left(0,000651 \times \mathrm{Mn}_{\text {tot }}\right)
\end{aligned}
$$

As variáveis preditoras (em $\mathrm{kg}$ ) que foram incluídas no modelo são as seguintes: adição de FeSiMn na panela (SiMn); adição de cal na panela (Calp); adição de coque na panela (Coque); adição de cal no convertedor ( $\left.\left.\mathrm{Cal}\right|_{\text {Id }}\right)$; adição de grafite na panela (Grafite) e somatório da adição de todas as ligas à base de ferro-manganês $\left(\mathrm{Mn}_{\mathrm{tot}}\right)$.

A avaliação do modelo de regressão apresentou os seguintes resultados: um valor de $\mathrm{R}$ de 0,9423 ; um valor de $\mathrm{R}^{2}$ de 0,8879 e um valor de $\mathrm{R}^{2}$ ajustado de 0,8777 . O valor elevado para o $\mathrm{R}^{2}$ ajustado indica que o modelo de regressão obtido conseguiu explicar a maior parte da variabilidade dos dados. A diferença entre o $\mathrm{R}^{2}$ e $\mathrm{R}^{2}$ ajustado é pequena, mostrando que todas as variáveis incluídas no modelo são significativas.

* Contribuição técnica ao 45 Seminário de Aciaria - Internacional, 25 a 28 de maio de 2014, 


\subsection{Resultados dos Experimentos (Entre RH E Ling. Contínuo)}

Foram realizados diversos experimentos no lingotamento contínuo, contemplando um total de 113 medições do teor de hidrogênio presente no aço líquido contido no distribuidor. Através dos experimentos realizados foi possível quantificar a incorporação de hidrogênio que ocorre no lingotamento contínuo, notadamente na $1^{\mathrm{a}}$ corrida do distribuidor. A Figura 4 mostra, apenas para as primeiras corridas do distribuidor, a queda do teor de hidrogênio verificada ao longo do lingotamento [6]. A opção pelo teor de hidrogênio relativo (H/Hfinal) foi feita para se evitar a dispersão dos valores devido ao tipo de aço das corridas utilizadas nos experimentos.

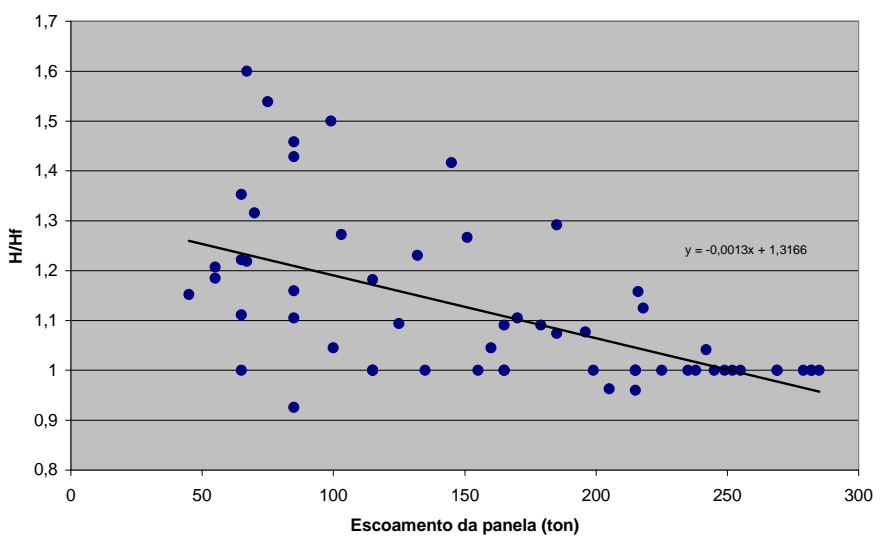

Figura 4. $\mathrm{H} / \mathrm{Hf}$ ao longo do lingotamento das primeiras corridas do distribuidor [6].

Por sua vez, as Figuras 5 e 6 mostram a influência do tipo de aquecimento do distribuidor (partida a quente $x$ partida a frio) e do tipo de material adicionado no distribuidor (pó de cobertura x palha de arroz), na evolução do teor de hidrogênio ao longo das primeiras corridas do distribuidor [6]. Aqui, novamente foi utilizado o teor de hidrogênio relativo (H/Hfinal).

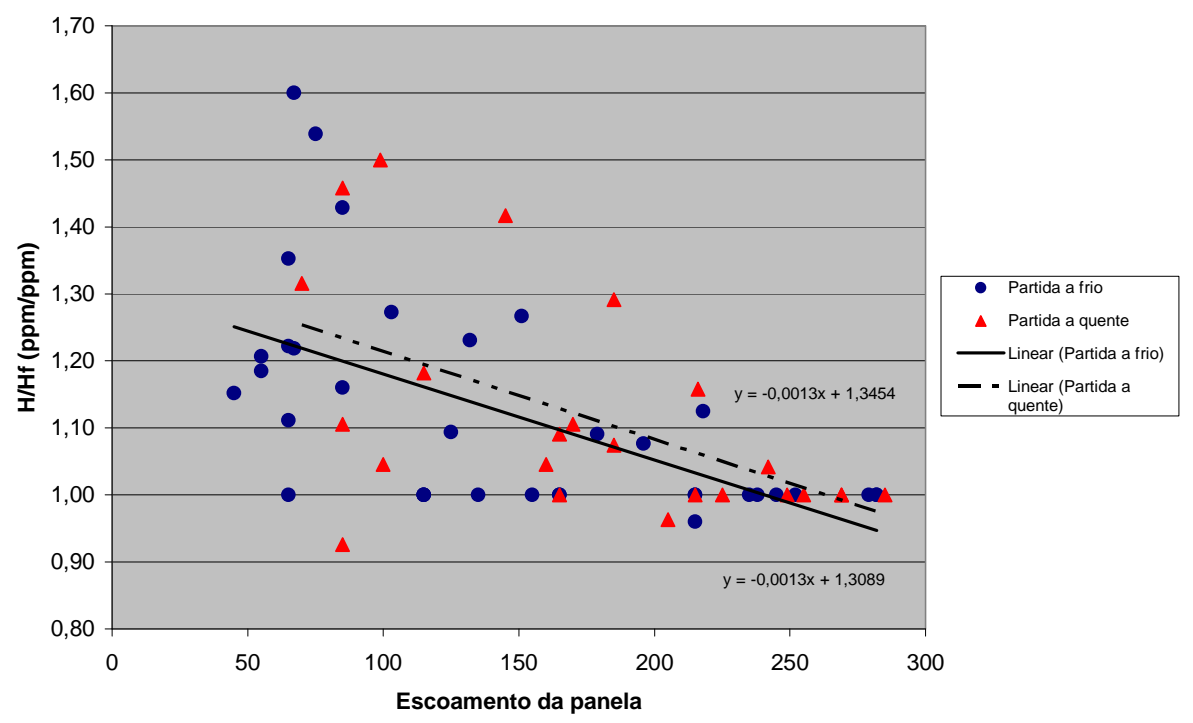

Figura 5. Evolução do H/Hf ao longo do lingotamento, em função do tipo de partida [6].

* Contribuição técnica ao 45 Seminário de Aciaria - Internacional, 25 a 28 de maio de 2014, Porto Alegre, RS, Brasil. 

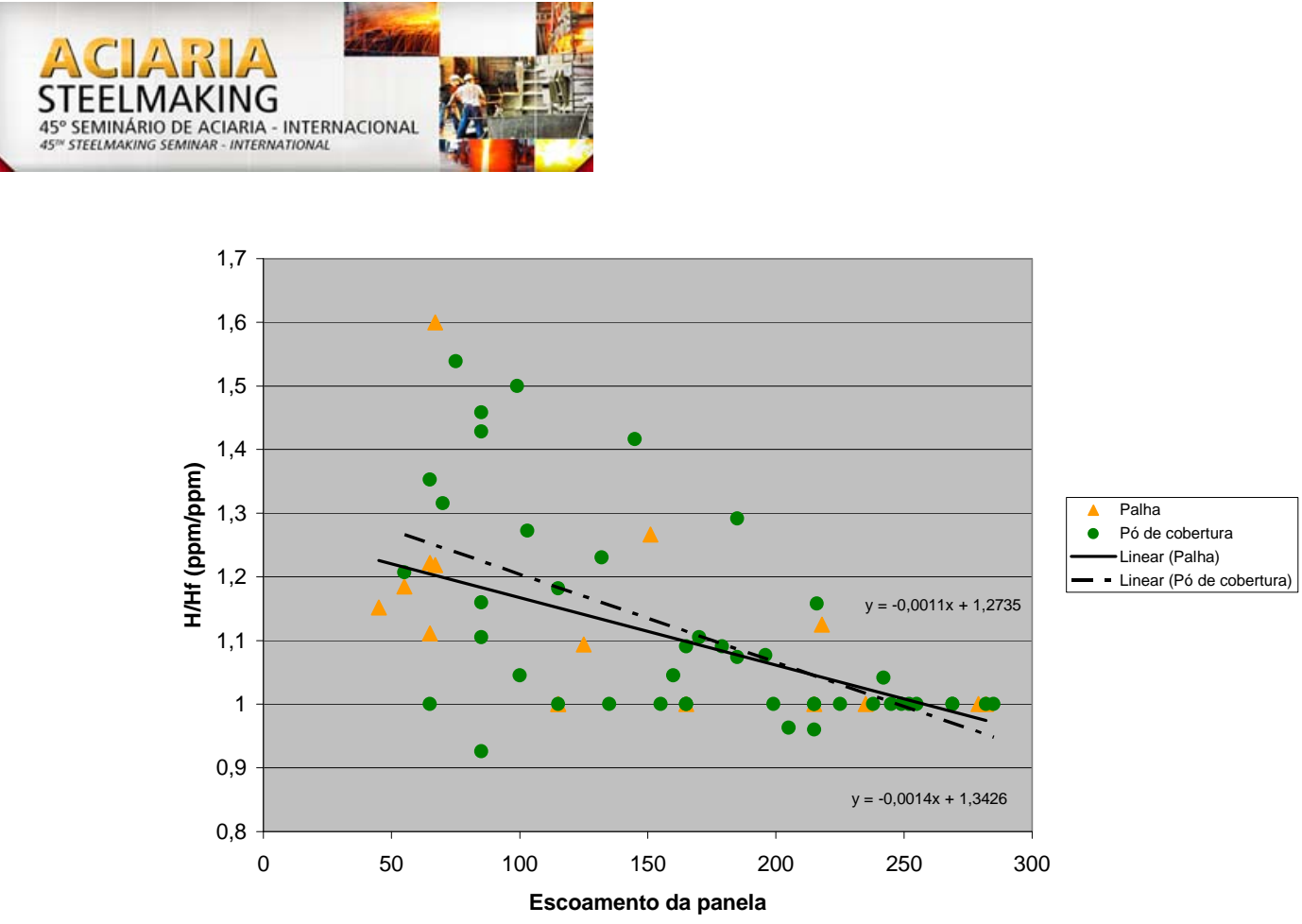

Figura 6. Evolução do $\mathrm{H} / \mathrm{Hf}$ ao longo do lingotamento, em função do tipo de material [6].

Os experimentos mostraram que as principais fontes de incorporação de hidrogênio durante o lingotamento da corrida são o revestimento refratário do distribuidor (e suas condições de secagem e aquecimento) e os materiais adicionados no distribuidor durante o lingotamento da corrida.

Verificou-se uma contaminação média de $42 \%$, afetando principalmente a $1^{\mathrm{a}}$ corrida do distribuidor. Em função do conhecimento adquirido, foi desenvolvido um padrão de liberação de corrida no $\mathrm{RH}$, conforme mostra a Tabela 2 abaixo, estabelecendo dois limites (conservador e máximo), para o teor de hidrogênio no fim do tratamento no $\mathrm{RH}$, visando a liberação da corrida para a área de lingotamento contínuo.

Tabela 2. Proposta de teor máximo de hidrogênio na liberação do refino para o contínuo

\begin{tabular}{|c||c||c||}
\hline $\begin{array}{c}\text { Limite superior de } \\
\text { hidrogênio de especificação } \\
(\mathrm{ppm})\end{array}$ & $\begin{array}{c}\text { Valor máximo de } \\
\text { hidrogênio para liberação } \\
\text { no refino (ppm) }\end{array}$ & $\begin{array}{c}\text { Valor conservador de } \\
\text { hidrogênio para liberação } \\
\text { no refino (ppm) }\end{array}$ \\
\hline 2 & 1,4 & 1,2 \\
\hline \hline 3 & 2,1 & 1,8 \\
\hline \hline 5 & 2,8 & 2,3 \\
\hline \hline 5 & 3,5 & 2,9 \\
\hline
\end{tabular}

Em resumo, a minimização da incorporação de hidrogênio no aço líquido, principalmente durante o lingotamento da corrida, e a liberação da panela no $\mathrm{RH}$ com no máximo 1,2ppm de hidrogênio (valor conservador), garante, de forma sustentável, a produção de aços com ultra baixos teores de hidrogênio, que é o objetivo geral do presente trabalho.

\subsection{Resultados dos Experimentos Realizados no RH}

O ponto de partida foi entender por que, em algumas ocasiões, não se obtém o mínimo teor de hidrogênio possível no fim do tratamento no $\mathrm{RH}$. Quais seriam as causas fundamentais que estariam impedindo este objetivo? Com as causas

* Contribuição técnica ao 45 Seminário de Aciaria - Internacional, 25 a 28 de maio de 2014, 
identificadas e quantificadas através de análise de regressão, partiu-se para a definição de uma solução em larga escala e para a realização de testes industriais.

\subsubsection{Causas potenciais para hidrogênio acima do permitido}

A Figura 7 mostra, através de um diagrama de causa e efeito, quais seriam as causas potenciais para o problema de se obter um teor de hidrogênio acima do permitido no fim do tratamento no $\mathrm{RH}$. Nesta etapa, foi identificado um total de 12 causas potencias que mais influenciavam no problema em questão.

Em seguida, utilizando-se um diagrama de matriz, foram priorizadas 7 causas potenciais, por apresentarem um relacionamento muito forte com o problema estudado. Estas causas potenciais prioritárias, todas do processo de produção no $\mathrm{RH}$, seriam: adição excessiva de ligas no $\mathrm{RH}$; momento incorreto de adição de ligas; deficiência no sistema de vácuo; aquecimento excessivo; tempo de tratamento inadequado; deficiência no sistema de gás inerte e teor inicial de hidrogênio muito elevado.

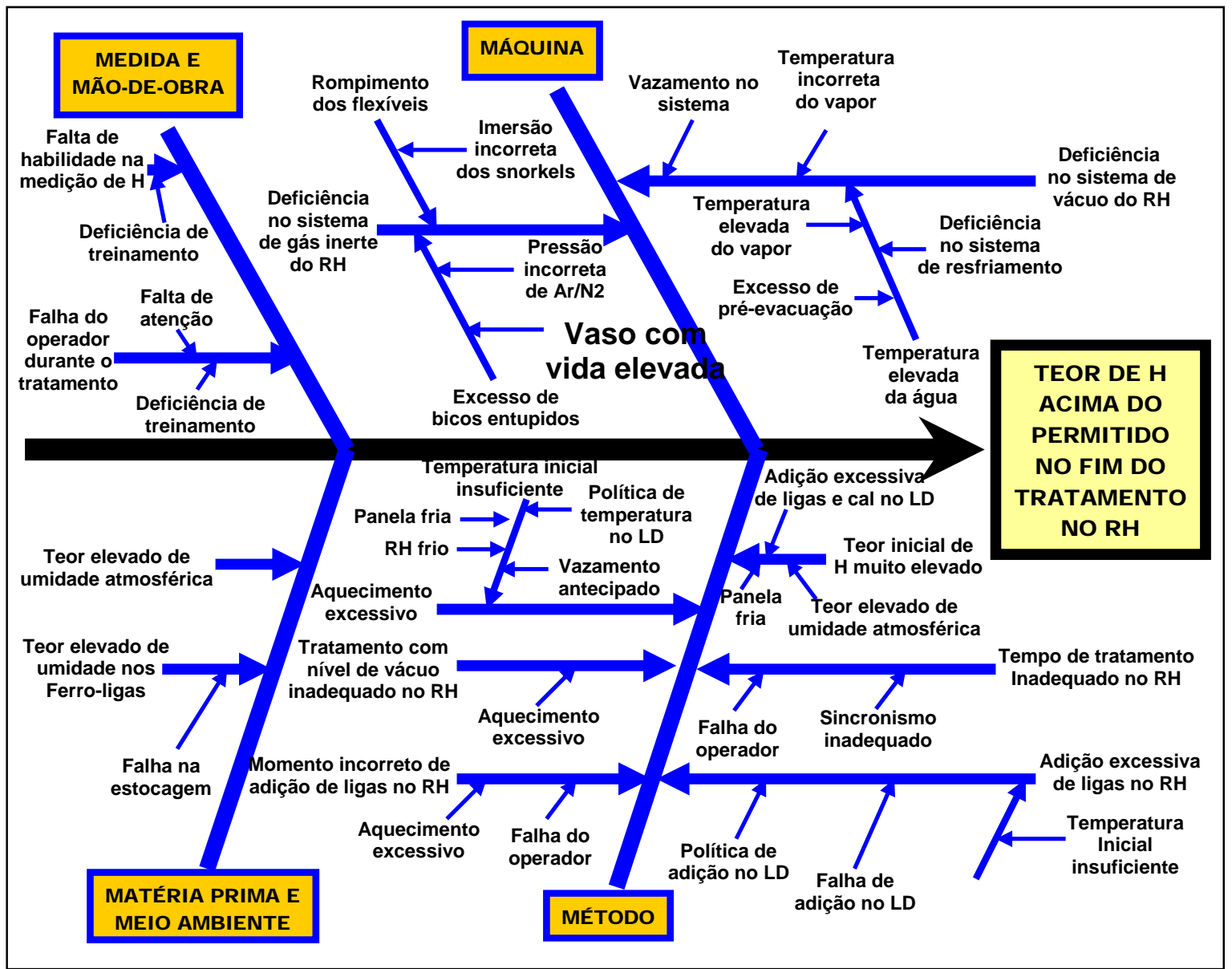

Figura 7. Diagrama de causa e efeito para teor de $\mathrm{H}$ acima do permitido no fim do tratamento no $\mathrm{RH}$.

\subsubsection{Modelo de previsão do teor final de hidrogênio no RH}

O verdadeiro grau de influência das causas potenciais prioritárias foi quantificado através do uso da ferramenta estatística "Análise de Regressão". Foram utilizadas 11 variáveis preditoras na forma simples. Essas 11 variáveis preditoras geraram, para a análise de regressão, um total de 66 variáveis preditoras dispostas nas formas linear, quadrática e interação linear. Um total de 191 dados reais do processo foi utilizado na análise de regressão.

* Contribuição técnica ao 450 Seminário de Aciaria - Internacional, 25 a 28 de maio de 2014, Porto Alegre, RS, Brasil. 
O modelo de regressão que procura fazer a predição do teor de hidrogênio presente no aço líquido, no fim do tratamento no $\mathrm{RH}$, é o seguinte:

$\mathrm{H}=1,639+0,000097^{*}(\mathrm{SiMn})+0,00018^{*}(\mathrm{FeMn})+0,000157^{*}(\mathrm{Cal})$

- 0,02998*(t_vác) $+0,000856 *($ Lig_RH $)+0,001112^{*}\left(\mathrm{O} \_s o p\right)$

Onde: SiMn, FeMn e Cal=pesos(kg) de FeSiMn, FeMn e Cal adicionados no convertedor; t_vác=tempo de vácuo(min) no $\mathrm{RH}$; Lig_RH=peso de ligas(kg) adicionado nos últimos 4 minutos de tratamento no $\mathrm{RH}$; O_sop=volume do oxigênio $\left(\mathrm{Nm}^{3}\right)$ soprado no $\mathrm{RH}$ e $\mathrm{H}=$ teor de hidrogênio no fim do tratamento no $\mathrm{RH}$ (ppm).

\subsubsection{Relevância das causas potencias prioritárias identificadas}

A relevância das causas prioritárias identificadas é notória em termos de dados de literatura e de trabalhos técnicos desenvolvidos no Brasil e no exterior. Por exemplo, a figura 8, com dados de processo da ArcelorMittal Tubarão, mostra a influência do tempo de vácuo no teor final de hidrogênio no $\mathrm{RH}$.

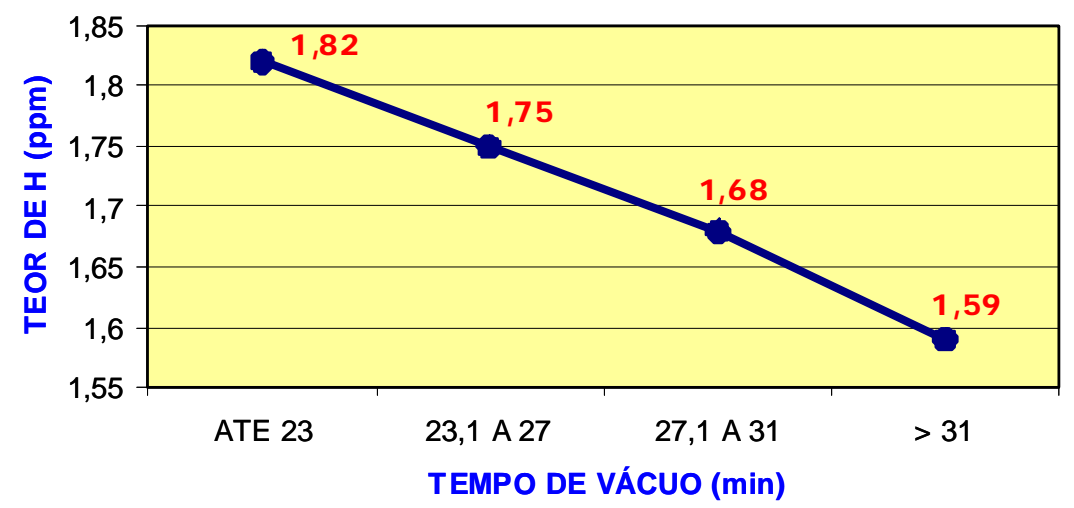

Figura 8. Influência do tempo de vácuo no teor final de hidrogênio no RH.

Por sua vez, as Figuras 9 e 10, também com dados da ArcelorMittal Tubarão, mostram o relacionamento entre volume de oxigênio soprado no $\mathrm{RH}$ e teor final de hidrogênio.

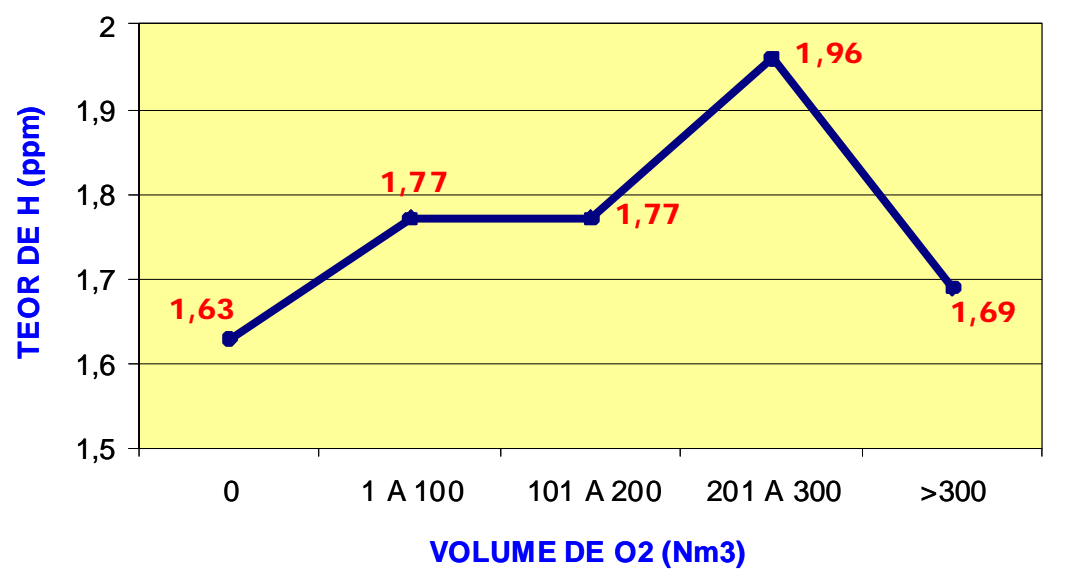

Figura 9. Influência do volume de oxigênio soprado no teor final de hidrogênio no RH.

* Contribuição técnica ao 450 Seminário de Aciaria - Internacional, 25 a 28 de maio de 2014, Porto Alegre, RS, Brasil. 


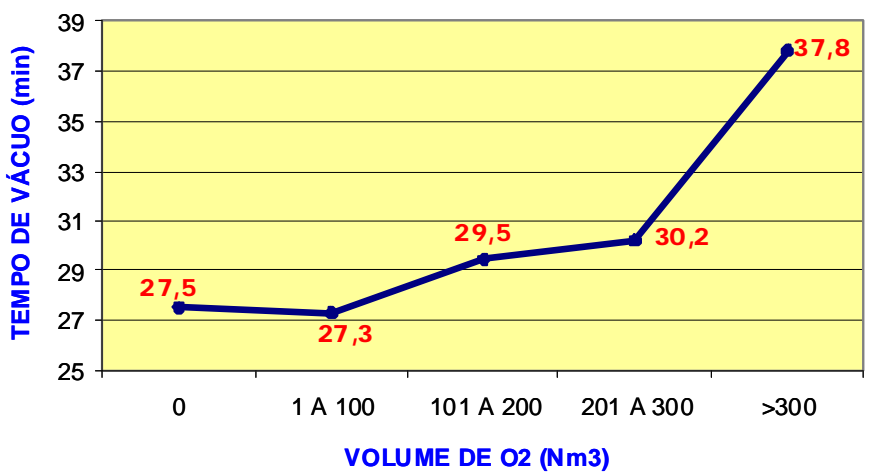

Figura 10. Influência do volume de oxigênio soprado no tempo de vácuo no RH.

\subsubsection{Resultados dos testes industriais no RH}

Após a definição das causas fundamentais que seriam investigadas, foi implementado um plano de ação, contemplando 17 soluções prioritárias. As premissas utilizadas na escolha das soluções prioritárias foram o baixo custo de implantação das soluções e o baixo impacto no processo operacional de produção de aços desidrogenados.

Definidas as soluções prioritárias, com as devidas avaliações de riscos, partiu-se para um teste piloto e, em seguida, para um teste industrial em larga escala. A Figura 11 apresenta os resultados deste teste em escala industrial. O teor médio de hidrogênio, no fim do tratamento no $\mathrm{RH}$, caiu de 1,75 para 1,09 ppm. Já o desvio padrão sofreu uma redução de 0,57 para 0,26 ppm.

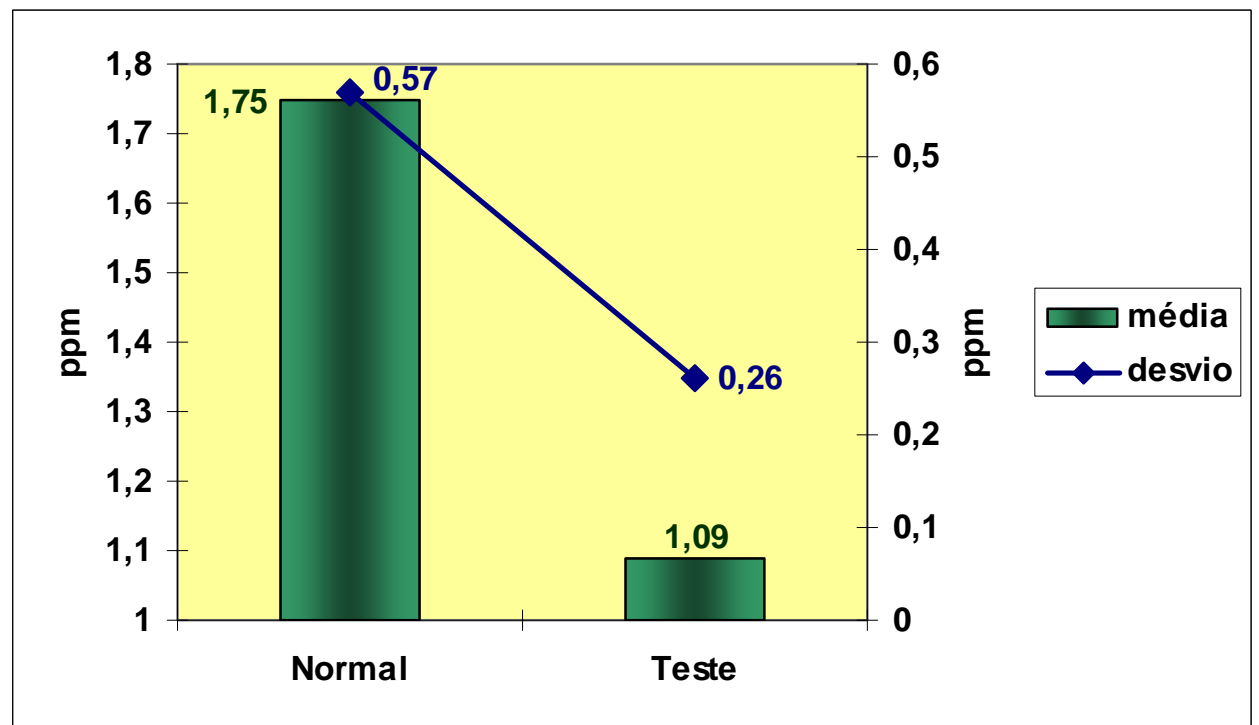

Figura 11. Evolução do teor médio de hidrogênio no fim do tratamento no RH.

A obtenção de um teor médio de hidrogênio de 1,09 ppm no fim do tratamento no $\mathrm{RH}$, de forma sustentável e sem comprometimento da produtividade do equipamento, demonstrou que o objetivo de maximização da taxa de remoção de hidrogênio no RH foi plenamente alcançado.

* Contribuição técnica ao 45 Seminário de Aciaria - Internacional, 25 a 28 de maio de 2014, Porto Alegre, RS, Brasil. 


\section{CONCLUSÃO}

O presente trabalho identificou e quantificou as principais fontes de incorporação de hidrogênio, atuantes no processo de produção de aço líquido da aciaria da ArcelorMittal Tubarão, desde o vazamento no convertedor até o fim do lingotamento da corrida. Os resultados obtidos se mostraram coerentes com diversos estudos e dados de literatura. As principais fontes de incorporação identificadas foram as adições de materiais recarburantes (coque e grafite); as adições de cal no convertedor (após o fim de sopro) e na panela; as adições de ferro-ligas (FeSiMn e somatório de diversas ligas de ferro-manganês) e o revestimento refratário dos distribuidores do lingotamento contínuo.

Com o conhecimento adquirido, foram desenvolvidos dois modelos matemáticos capazes de prever os teores de hidrogênio no início e no fim do tratamento no $\mathrm{RH}$, para cada corrida de aço desidrogenado produzida. Foi através destes modelos que se quantificou a importância relativa de cada fonte de incorporação de hidrogênio identificada. A análise de regressão linear múltipla, para o teor inicial de hidrogênio no $\mathrm{RH}$, conseguiu estabelecer um modelo capaz de explicar a maior parte da variabilidade do teor de hidrogênio medido no aço líquido.

Ainda com relação às fontes de incorporação de hidrogênio no aço líquido, a lição a ser assimilada é a de que uma vez que não se pode evitar o uso das fontes de incorporação de hidrogênio identificadas, deve-se, pelo menos, escolher o momento mais apropriado para que as mesmas sejam adicionadas na panela de aço líquido.

A obtenção de um teor médio de hidrogênio de 1,09ppm no fim do tratamento no RH e a minimização da incorporação de hidrogênio no aço líquido, principalmente durante o lingotamento da corrida, garantiu, de forma sustentável e sem comprometimento da produtividade da aciaria, a produção de aços com ultra baixos teores de hidrogênio, que é o objetivo geral do presente trabalho.

\section{REFERÊNCIAS}

1 Warren D. Hydrogen effects on steel, National Association of Corrosion Engineers. Materials Performance. 1987;26(1):38-48.

2 Fuji T. Estudo da incorporação e controle do hidrogênio e nitrogênio na aciaria [dissertação de mestrado]. Belo Horizonte: Pós-graduação em Engenharia Metalúrgica e de Minas da UFMG; 2003. p.160.

3 Fuwa T. Hydrogen and nitrogen in liquid iron alloys. In: International Conference on the Physical Chemistry of Iron and Steelmaking; 1978; Versailles, France. p.186-193.

$4 \quad$ Winkler O, Bakish R. Vacuum Metallurgy. $1^{\mathrm{a}}$ ed. Amsterdam: Elsevier; 1971. p.890.

5 Frigm G, Stone RP, Plessers J, Bogan RS, Turkdogan ET. Experimental determination of the accuracy of hydrogen measurement in liquid steel with HYDRIS System. Electric Furnace Conference Proceedings. ISS; 1990. vol.48, p.83-93.

6 Fialho MM, Furtado HS, Santos SS. Análise da contaminação por hidrogênio no lingotamento contínuo da CST. In: ABM. $36^{\circ}$ Seminário de Fusão, Refino e Solidificação dos Metais; 2005; Vitória, Brasil. São Paulo: ABM; 2005.

* Contribuição técnica ao 45 Seminário de Aciaria - Internacional, 25 a 28 de maio de 2014, 